\title{
Reactive DWC leading the way to FAME and fortune
}

\author{
Anton Alexandru Kiss ${ }^{\mathrm{a}, *}$, Juan Gabriel Segovia-Hernández ${ }^{\mathrm{b}}$, Costin Sorin Bildea ${ }^{\mathrm{c}}$, \\ Erick Yair Miranda-Galindo ${ }^{\mathrm{b}}$, Salvador Hernández ${ }^{\mathrm{b}}$ \\ ${ }^{a}$ Akzo Nobel Research, Development E Innovation, Process Technology ECG, Zutphenseweg 10, 7418 AJ Deventer, The Netherlands \\ ${ }^{\mathrm{b}}$ Universidad de Guanajuato, Campus Guanajuato, División de Ciencias Naturales y Exactas, Dept. de Ingeniería Química, Noria Alta s/n, 36050 Guanajuato, Gto., Mexico \\ ' University "Politehnica" of Bucharest, Department of Chemical Engineering, Polizu 1-7, 011061 Bucharest, Romania
}

\section{A R T I C L E I N F O}

\section{Article history:}

Received 19 July 2011

Received in revised form 10 November 2011

Accepted 29 December 2011

Available online 11 January 2012

\section{Keywords:}

Biodiesel

Reactive DWC

Catalytic distillation

Simulated annealing

Optimal design

\begin{abstract}
A B S T R A C T
Reactive separation processes were recently proposed for the synthesis of fatty acid methyl esters (FAMEs), most of them making use of solid catalysts thus eliminating all conventional catalyst-related operations, improving process efficiency and reducing energy requirements. Such integrated systems require a stoichiometric reactants ratio in order to achieve complete conversion and high purity products. However, maintaining this ratio can be very difficult in practice, especially when the fatty acids feed composition is not constant in time.

This study proposes a novel biodiesel process based on a reactive dividing-wall column (R-DWC) that allows the use of only $\sim 15 \%$ excess of methanol to completely convert the fatty acids feedstock. FAME are produced as pure bottom product, water as side stream, while the methanol excess is recovered as top distillate and recycled. The design is a challenging global optimization problem with discrete and continuous decision variables. The optimal setup was established by using simulated annealing as optimization method implemented in Matlab, and coupled with rigorous simulations carried out in Aspen Plus. Along with the FAME production, the novel design alternatives allow a fortune to be saved by reducing the energy requirements with over $25 \%$ and by using less equipment units than conventional processes.
\end{abstract}

(c) 2012 Elsevier Ltd. All rights reserved.

\section{Introduction}

Renewable energy sources are developed worldwide due to the volatile oil prices and increased greenhouse gas emissions. At present, employing waste and non-edible raw materials is mandatory to comply with the ecological and ethical requirements for biofuels. Biodiesel - emerged as a viable alternative to petroleum diesel - is a renewable fuel consisting of fatty acid methyl esters (FAMEs). These esters are currently produced mainly from green sources such as vegetable oils, animal fat or waste cooking-oils $[15,49]$. The most widespread manufacturing technologies use homogeneous catalysts, in processes where both reaction and separation steps can create bottlenecks.

The use of inexpensive waste oils received increased attention lately, due to the high cost of the refined vegetable oils [34,39,9]. Remarkably, the 'food versus fuel' competition is clearly avoided when the raw materials used are waste vegetable oils or non-food crops such as Jatropha, Karanja, Polanga [43] and Mahua [20]. Zhang et al. [55] showed that using waste oils can have a very positive impact on the economics of biodiesel processes. However,

\footnotetext{
* Corresponding author. Tel.: +3126366 9420.

E-mail addresses: Tony.Kiss@akzonobel.com, TonyKiss@gmail.com (A.A. Kiss).
}

the waste raw materials contain a substantial amount of free fatty acids (FFAs) thus not being compatible with current processes. Accordingly, the development of an efficient continuous process for FAME manufacturing is required, in which the use of a solid catalyst is especially wanted in order to suppress the costly chemical processing steps and the waste treatment.

Note that all conventional biodiesel processes suffer from problems associated with the use of homogeneous catalysts, leading to severe economical and environmental penalties. Consequently, tremendous research efforts are devoted to the development of solid catalysts for biodiesel production [22,23,37,45,54]. Moreover, process intensification methods can be further employed in order to reduce investment and operating costs, simplify the downstream processing steps, and minimize the waste streams [41]. Reactive separations such as reactive distillation (RD), reactive stripping or absorption (RA) were recently proposed as innovative processes for FAME synthesis by esterification of fatty acids using solid acid catalysts $[23,24,27,11,25,4]$. Note that by integrating reaction and separation into one unit (e.g. RD) the equilibrium of the reaction can be completely shifted toward FAME formation by continuously removing the products.

Dividing-wall column (DWC), combining distillation with distillation, is another process intensification method developed decades ago and already implemented at industrial scale. Remarkably, DWC 
is the only known large scale process intensification example where both capital and operating costs can be vastly reduced, with the additional benefit of reducing the required installation space by up to $40 \%[8,3]$. Moreover, DWC is not limited to ternary separations only but it can be used also in extractive distillation [6], azeotropic separations [32], and reactive distillation [36,17,26,33]. DWC is considered a major breakthrough in distillation, as it brings significant reduction in CapEx and OpEx - up to 30-40\% [19,8]. The design, control and applications of DWC are now established $[42,13,10,8,29,30]$ although hurdles are still perceived for their extended industrial applications [16]. Fig. 1 illustrates the evolution of conventional distillation to the reactive distillation or dividing-wall column and the emerged integrated reactive DWC [52].

This study proposes a novel biodiesel process based on a reactive dividing-wall column that allows the use of a small excess of methanol to completely convert the fatty acids feedstock. FAME is produced as pure bottom product, water by-product as side stream, while the methanol excess is recovered as top distillate and recycled. The optimal configuration was established by using simulated annealing as an optimization method implemented in Matlab and coupled with rigorous Aspen Plus simulations. Along with the FAME production, the generated improved design alternatives allow a fortune to be saved by reducing the energy requirements by over $25 \%$, at lower investment costs as compared to conventional processes.

\section{Problem statement}

Conventional biodiesel processes are plagued by the drawbacks of using homogeneous catalysts as well as the high energy requirements. Fig. 2 illustrates the large energy use implied by a two-step biodiesel process - esterification of FFA followed by the transesterification of tri-glycerides [48]. Remarkably, the recovery of the huge excess of methanol and the purification of the FAME product account for most energy use.

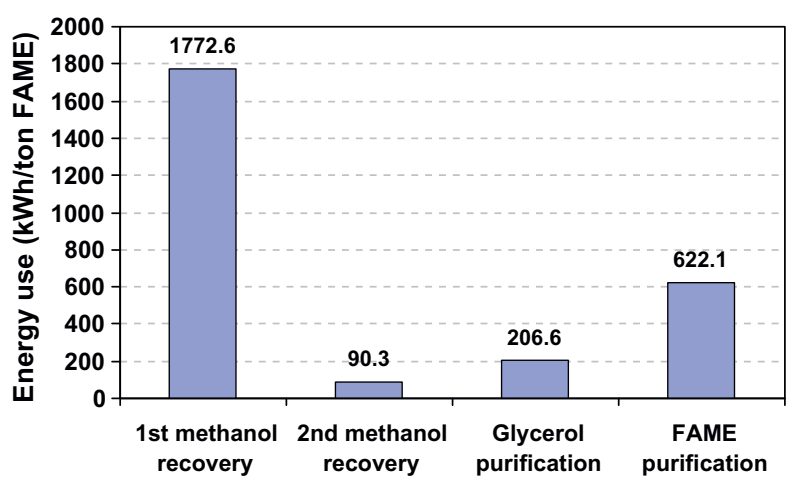

Fig. 2. Energy requirements for a conventional two-step biodiesel process.

As previously described, several reactive separation processes such as reactive distillation or reactive absorption were proposed for the biodiesel production [31]. Most of these processes make use of solid acid/base catalysts thus eliminating all conventional catalyst related operations, improving efficiency and reducing the energy requirements for the biodiesel production.

The problem of these reactive separation systems is that a stoichiometric ratio of reactants is required in order to allow complete conversion of the fatty raw materials and production of two high purity products (e.g. water by-product as top distillate and FAME as bottom product). However, maintaining the stoichiometric ratio in practice can be difficult especially when the composition of the fatty acids feed is not continuously monitored or not known.

To solve this problem and still maintain all the advantages of $\mathrm{RD}$, we developed a novel design based on a reactive DWC - a particular implementation of the classic Petlyuk configuration $[8,18]$. This allows the use of a slight excess of methanol ( $15 \%$ or higher), while still delivering pure products - methanol as top distillate that can be recycled, water by-product as side stream and FAME as bottom product.

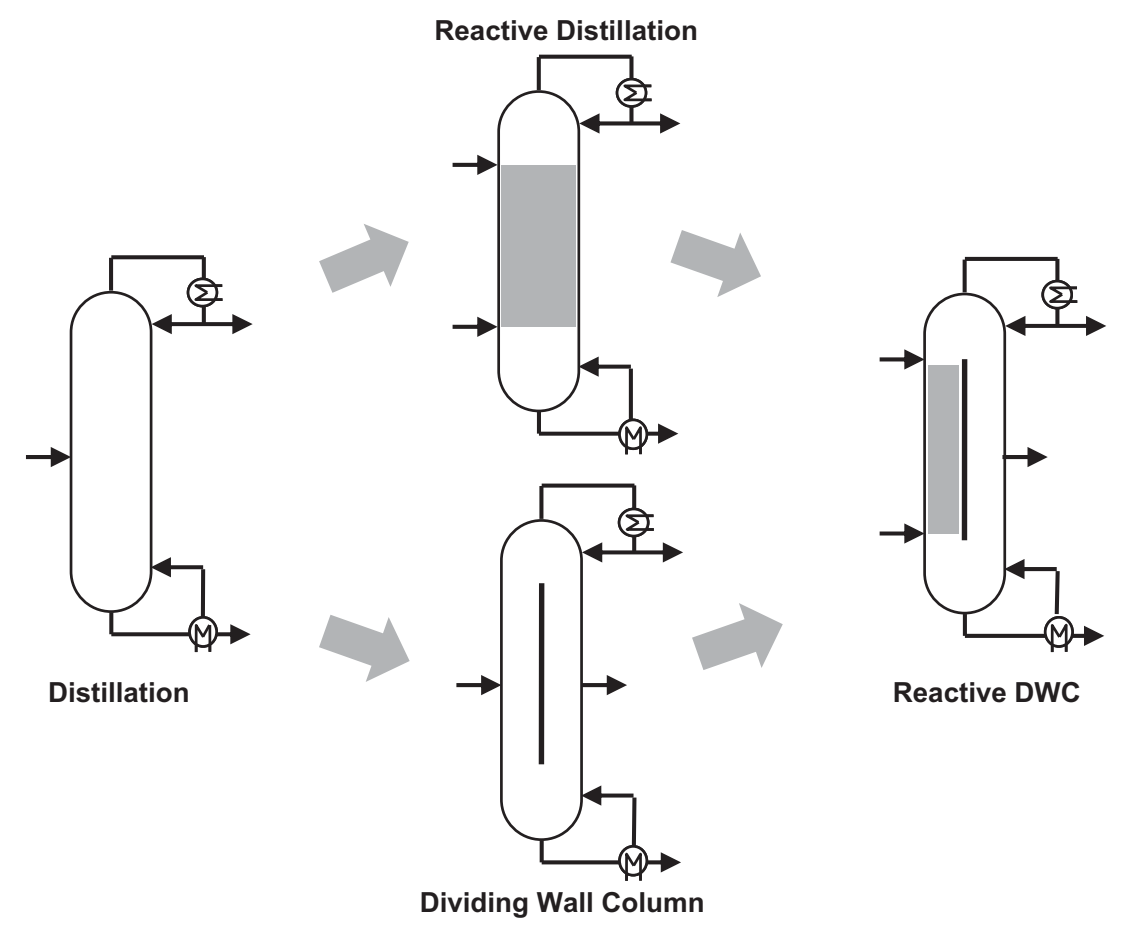

Fig. 1. Schematics of evolution from distillation to reactive dividing wall column. 
Table 1

Values of the parameters used in the simulated annealing.

\begin{tabular}{ll}
\hline SA parameter & Value \\
\hline Annealing function & Boltzman \\
Reannealing interval & 100 \\
Temperature update & Linear \\
Initial temperature & 100 \\
\hline
\end{tabular}

\section{Optimization strategy}

In this work we make use of simulated annealing (SA) as optimization strategy. Simulated annealing mimics the thermodynamic process of cooling of molten metals to attain the lowest free energy state [21]. Starting with an initial solution, the algorithm performs a stochastic partial search of the space defined for decision variables. In minimization problems, uphill moves are occasionally accepted with a probability controlled by the parameter called annealing temperature $\left(T_{\mathrm{SA}}\right)$. The probability of acceptance of uphill moves decreases as $T_{\mathrm{SA}}$ decreases. At high $T_{\mathrm{SA}}$, the search is almost random, while at low $T_{\mathrm{SA}}$ the search becomes selective where good moves are favored. The core of this algorithm is the Metropolis criterion [35,51] that is used to accept or reject uphill movements with an acceptance probability given by:

$M\left(T_{S A}\right)=\min \left\{1, \exp \left(\frac{-\Delta f}{T_{S A}}\right)\right\}$

where $\Delta f$ is the change in objective function value from the current point to the new point.

The objective function is evaluated at the trial point, and its value is compared to the objective value at the starting/current point. Eq. (1) is used to accept or reject the trial point. If this trial point is accepted, the algorithm continues the search using that point. Otherwise, another trial point is generated within the neighbourhood of the starting/current point. A fall in $T_{\mathrm{SA}}$ is imposed upon the system using a proper cooling schedule. Thus, as $T_{\mathrm{SA}}$ declines, uphill moves are less likely to be accepted and SA focuses on the most promising area for optimization. These iterative steps are performed until the specified stopping criterion is satisfied. The random numbers can be uniformly distributed in the interval $[0$, 1]. If the condition rand $\angle M\left(T_{\mathrm{SA}}\right)$ is fulfilled, then the trial point is being accepted. Otherwise the starting/current point is used to start the next step. The temperature $T_{\mathrm{SA}}$ can be considered a control parameter. The initial temperature $\left(T_{i}\right)$ is related to the standard deviation of the random perturbation, and the final temperature $\left(T_{f}\right)$ with the order of magnitude of the desired accuracy gives the location of the optimum. Note that until now, the SA algorithm was already successfully used in several chemical engineering applications by Rangaiah [40], Bonilla-Petriciolet et al. [5], Wei-Zhong and Xi-Gang [50] among others.

In order to optimize the complex reactive DWC previously described, we use the SA implementation in Matlab [46]. The SA parameters were tuned using several short tests in order to improve the efficiency of the stochastic method, while the initial point of SA was created randomly in the feasible region. Table 1 shows the values of the key parameters used in the simulated annealing.

Specifically, for process design of complex separation schemes, the minimization of the heat duty of the distillation column is the optimization target. Notably, up to $80 \%$ of the total annual costs (TACs) are associated to the energy requirements even for complex distillation columns. Consequently, the use of the heat duty is always a good approximation of the TAC. Moreover, the energy use
Table 2

Types of the optimization variables used in the SA optimization.

\begin{tabular}{ll}
\hline Optimization variable & Type \\
\hline Temperature, $T$ & Continuous \\
Reactive stages, $N_{R}$ & Discrete \\
Total number stages, $N_{\text {DWC }}$ & Discrete \\
Distillate rate, $D$ & Continuous \\
Side stream product flowrate, $F_{\text {SIDESTR }}$ & Continuous \\
Boilup ratio, $V$ & Continuous \\
Stage of side stream product, $N_{\text {SIDESTR }}$ & Discrete \\
Recycle location, $N_{\text {RECYCLE }}$ & Discrete \\
Liquid split, $r_{L}$ & Continuous \\
Vapor split, $r_{V}$ & Continuous \\
\hline
\end{tabular}

is also directly linked to the $\mathrm{CO}_{2}$ emissions. In the reactive DWC, the optimization problem for the minimization of the reboiler heat duty is defined as:

$$
\begin{aligned}
& \operatorname{Min}(Q)=f\left(T, N_{R}, N_{D W C}, D, F_{\text {SIDESTR }}, V, N_{\text {SIDESTR }}, N_{R E C Y C L E}, r_{V}, r_{L}\right) \\
& \text { subject to } \vec{y}_{m} \geqslant \vec{x}_{m}
\end{aligned}
$$

where $T$ is the temperature in the FFA heater, $N_{\mathrm{R}}$ is the number of reactive stages, $N_{\text {DWC }}$ is the total number of stages in the DWC, $D$ is the distillate rate, $F_{\text {SIDESTR }}$ is the side stream product flowrate, $V$ is the boilup ratio, $N_{\text {SIDESTR }}$ and $N_{\text {RECYCLE }}$ are the side stream product and recycle location, while $r_{L}$ and $r_{V}$ are the liquid and vapor split, while $y_{m}$ and $x_{m}$ are vectors of obtained and required purities for the $m$ products, respectively. This design problem is a challenging global optimization problem with discrete and continuous decision variables (Table 2 ).

The optimal design of the reactive DWC was found by using simulated annealing (SA) as an optimization method implemented in Matlab and coupled with Aspen Plus simulations [1,2]. Fig. 3 shows the connection of Mathworks Matlab with AspenTech Aspen Plus via MS Excel, including the flow of data between these programs. During the evolution of the SA, the vector values of decision variables $\left(V_{x}\right)$ are sent from Matlab to Microsoft Excel using DDE (dynamic data exchange) by COM technology. These values are attributed in Excel to the corresponding process variables $\left(V_{p}\right)$ and then sent to Aspen Plus by a similar interface. Note that using the COM technology it is possible to add code such that the applications behave as an Object Linking and Embedding (OLE) automation server. After running the rigorous simulation, Aspen Plus returns to MS Excel the vector of results $\left(V_{r}\right)$. Finally, Excel returns the objective function $\left(F_{O B}\right)$ value to Matlab for the SA procedure. Note that the CPU time is high for each optimization step due to the long convergence time required by the Aspen Plus simulator that ensures rigorous process simulation results. However, the CPU time of SA is typically much lower than that of Genetic Algorithm (GA) and Harmony Search (HS) especially in design problems of complex distillation sequences [7].

\section{Results and discussion}

The integrated RD process was designed according to previously reported process synthesis methods for reactive separations $[44,38,36]$. Rigorous simulations embedding experimental results were performed using Aspen Plus [1,2]. The RD column was simulated using the rigorous RADFRAC unit with RateSep (rate-based) model enabled, and explicitly considering three phase balances. Phase splitting must be accounted for, as free water phase can deactivate the solid acid catalyst. Nevertheless, as later revealed by the composition profiles, the molar fraction of water in the liquid phase does not exceed 0.1 on the reactive stages. Therefore, the catalyst deactivation does not occur here, under the designed process conditions. 


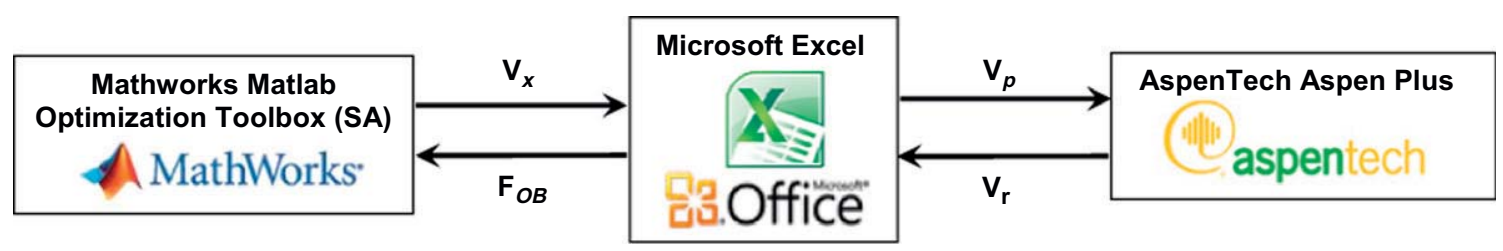

Fig. 3. Connection of Mathworks Matlab with AspenTech Aspen Plus via MS Excel.

The physical properties required for the simulation and the binary interaction parameters for the methanol-water and acid-ester pairs were available in the Aspen Plus database of pure components, while the other interaction parameters were estimated using the UNIFAC - Dortmund modified group contribution method $[1,2]$. Similar results are obtained using other state-of-the art estimation methods, such as UNIFAC and UNIFAC - Lyngby modified $[1,2]$. The fatty components were conveniently lumped into one fatty acid and its fatty ester, according to: R-COOH + $\mathrm{CH}_{3} \mathrm{OH} \leftrightarrow \mathrm{R}-\mathrm{COO}-\mathrm{CH}_{3}+\mathrm{H}_{2} \mathrm{O}$. Dodecanoic (lauric) acid/ester was selected as lumped component due to the availability of experimental results and VLLE parameters for this system [23,11]. The assumption of lumping components is very reasonable since fatty acids and their corresponding fatty esters have similar properties $[53,25]$. This approach was already reported to be successfully used in simulating other FAME production processes $[23,24,11,25]$. In this work, sulfated zirconia is considered as solid acid catalyst, since kinetic data for the esterification with methanol is available from previous work $[24,11,25]$. Fig. 4 shows the proposed flowsheet. The conceptual design of the process is based on a reactive DWC that integrates the reaction and separation steps into a single operating unit. By combining reaction and separation, one can shift the reaction equilibrium towards products formation by continuous removal of reaction products, instead of using an excess of reactant. Since methanol and water are much more volatile than the fatty ester and acid, these will separate easily as top distillate and side stream. High conversion of the reactants is achieved, with the productivity of the RD unit exceeding $20 \mathrm{~kg}$ fatty ester $/ \mathrm{kg}$ catalyst/h and the purity specifications over $99.9 \mathrm{wt} \%$ for the final bio- diesel product (FAME stream). Note that heat integration methods [28-30] could be applied to further enhance the energy savings, but this is beyond the scope of the current study. Fig. 5 shows the liquid and vapor composition, while Fig. 6 plots the temperature profile along the reactive DWC. Similar profiles were obtained also for the alternative designs. The concentration of the fatty acid and methanol is high at the top of the column, while the fatty esters concentration increases from the top to bottom. Therefore, the water accumulated in the middle zone is removed as side stream, while FAME delivered as high purity bottom product.

The tray arrangements and the most important design variables for the base case and the optimal R-DWC structures are given in Table 3. Remarkably, energy savings of up to $25 \%$ can be achieved, just by properly tuning the design of the reactive DWC. It can be seen that the total number of stages in the optimized DWCs is higher in comparison to the base case and consequently the number of reactive stages is increased. An important point is that the optimized designs also comply with all the restrictions on the purities and recoveries of the products. Consequently, an important issue is reviewing the feasibility to obtain the purity of $99.9 \mathrm{wt} \%$ for FAME in all these reactive schemes. The results shown in Table 3 clearly indicate that it is indeed feasible to obtain biodiesel of very high purity in all schemes.

The improved alternatives (S2-S7) were generated by the simulated annealing algorithm previously described. The SA method is stochastically by nature, so it has two well-known advantages: it can be readily connected to highly sophisticated simulators - such as Aspen Plus - and it converges towards a global optimum as computing time approaches infinity. In practice, it finds the global

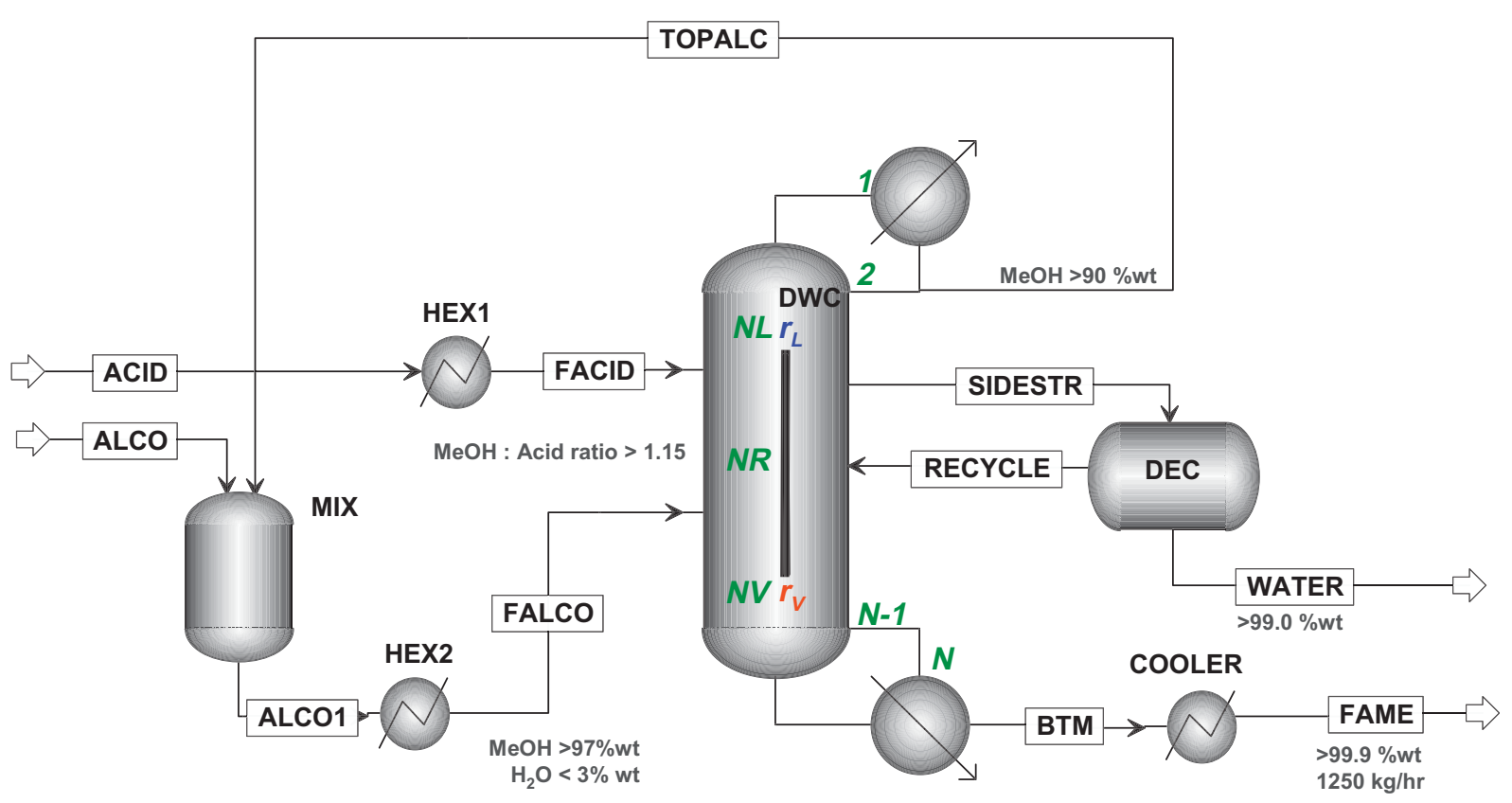

Fig. 4. Flowsheet and topology of reactive DWC for FAME production: N - number of stages, NR - number of reactive stages, NL - liquid split stage, NV - vapor split stage. 

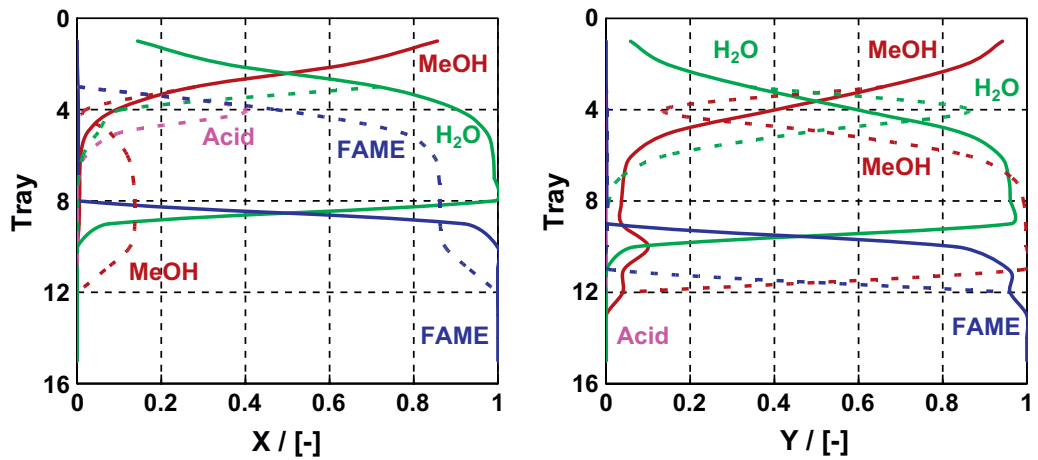

Fig. 5. Liquid and vapor molar composition profiles along the reactive DWC (base case).

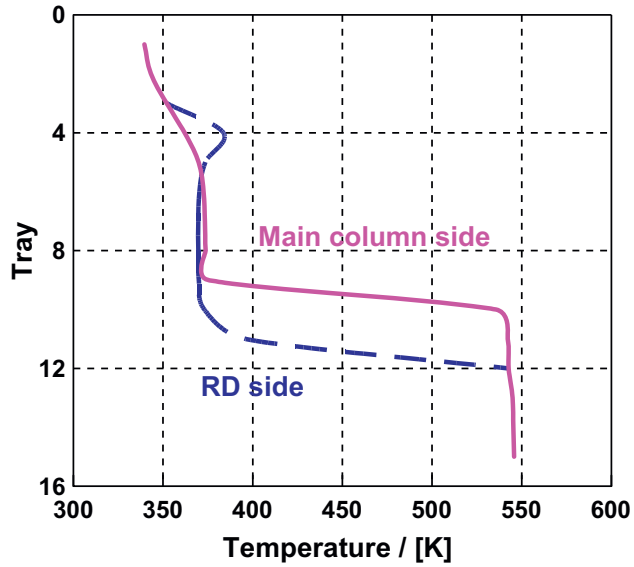

Fig. 6. Temperature profiles along the reactive DWC (base case).

optimality very efficiently [14,51]. The evolution course of the best function value for the SA is conveniently shown in Fig. 7, while Table 3 provides the best solution (S7) along with other five configurations (S2-S6) evaluated every 1000 iterations. It can be seen that a great number of the function values are jumped off as the optimization method reduces the best function value. Note that the stopping criterions commonly used in stochastic algorithms are based on the maximum number of successive iterations $\left(\mathrm{Sc}_{\max }\right)$ without improvement in the best function value, the number of iterations $\left(\right.$ Iter $\left._{\text {max }}\right)$ or the CPU time limit $\left(\mathrm{CPU}_{\text {time }}\right)$. Some studies report from 1000 to 2500 iterations to find the best function value which is taken as the optimal solution in distillation process [14,50]. In this work, the searching process stops when the iteration number reaches 10,000 , hence after a much longer interval.

Notably, the design with the greatest savings in energy requirements (Case S7) shows the largest total number of stages and reactive stages as compared to the base case. It can be seen that the total number of stages and reactive stages are 140\% and $162.5 \%$ higher than those of the base case (Case S1). These results are used to conduct a study on the total annual cost of operating these systems in order to see the impact of the equipment cost and utilities cost on the total annual cost. In this way the designer could make decisions about how much is the amount of energy savings that the equipment should have, without a high increment in the total annual cost due to the increase in the number of stages.

To complement this work, the total annual cost (TAC) was also estimated for the optimized designs of the reactive distillation columns. The cost of the columns made of carbon steel, was estimated by the cost equations described by Turton et al. [47], conveniently updated with the CEPCI (Chemical Engineering Process Cost Index). For comparison, a single value of CEPCI was selected, as of March, 2011. The total annual cost is the sum of the installed cost of column shell and the installed cost of the trays. Also, the sizing and costing of the heat exchangers and the auxiliary equipment were calculated and included. For example, the cost of heat exchangers can be correlated as a function of the surface area. The installation cost is also updated by using the CEPCI index. The capital cost purchase plus installation cost - is annualized over a period, which is often referred to as the plant lifetime:

Annual capital cost $=$ Capital cost/Plant life time

TAC $=$ Annual operating cost + Annual capital cost

The operating costs were calculated based only on the utility costs (steam and cooling water), while the plant lifetime was considered five years, with an operating time of $8400 \mathrm{~h} / \mathrm{yr}$.

The results shown in Table 3 indicate that cases S2, S6, and S7 showed similar TAC values to the base case (S1) that is the case that presents the lowest value of TAC. Note that the design S7 is the one with the greatest energy savings as compared to the base case S1. Additionally, the S7 design features a larger number of stages. However, the value of TAC does not significantly reflect this wide variation in the number of stages. For S2 and S6 designs that show similar TAC values when compared with the case S1 - even when they have a larger number of stages. It is important to note that S2 design shows no significant energy savings, while design S6 gives the second best energy savings. Consequently, the two best designs from the viewpoint of energy saving and TAC value are cases S6 and S7.

In distillation systems, such as crude oil distillation units, carbon dioxide is generated mainly from furnaces, gas turbines, and boilers. These utility devices are the fuel consumers in the refining plants and are used to provide heat, steam, and power to the process by burning a fuel. Therefore, these units are key drivers in energy savings oriented projects and reducing environmental emissions impacts. In this paper we estimate the values of green house gas emissions (GHG) by the technique proposed by Gadalla et al. [12]. As shown in Table 3, the optimal design S7 shows lower values of $\mathrm{CO}_{2}$ emissions compared to other designs, even compared to the S6 design, which is the second best design according to the TAC value.

Concerning the environmental aspects, the green house gas (GHG) emissions are directly linked to the energy use - since in the chemical industry the energy required in distillation is obtained from crude oil. As a result, any reductions in energy requirements can be directly translated into reductions in carbon dioxide emissions. Note that carbon dioxide emissions can increase significantly when the operational conditions are different from the 
Table 3

Design parameters for the reactive DWC: base case vs designs found by SA.

\begin{tabular}{|c|c|c|c|c|c|c|c|}
\hline & S1 & $\mathrm{S} 2$ & S3 & S4 & S5 & S6 & S7 \\
\hline \multicolumn{8}{|l|}{ Column topology } \\
\hline Number of stages, $N$ & 15 & 20 & 39 & 33 & 34 & 35 & 36 \\
\hline Number of reactive stages, NR & 8 & 11 & 24 & 20 & 21 & 19 & 21 \\
\hline Liquid split stage, $\mathrm{NL}$ & 3 & 5 & 8 & 7 & 7 & 8 & 8 \\
\hline Vapour split stage, NV & 12 & 16 & 32 & 27 & 28 & 27 & 29 \\
\hline Side-draw stage, N1 & 8 & 12 & 30 & 18 & 18 & 17 & 13 \\
\hline Organic phase-return stage, N2 & 3 & 9 & 28 & 7 & 25 & 25 & 26 \\
\hline \multicolumn{8}{|l|}{ Feed streams } \\
\hline ACID flowrate $(\mathrm{kmol} / \mathrm{h})$ & 5.83 & 5.83 & 5.83 & 5.83 & 5.83 & 5.83 & 5.83 \\
\hline Temperature HEX1 (K) & 418.1 & 385.6 & 373.2 & 410.4 & 428.1 & 423.2 & 418.9 \\
\hline ALCO flowrate $(\mathrm{kmol} / \mathrm{h})$ & 6.8 & 6.997 & 6.997 & 6.997 & 6.997 & 6.997 & 6.997 \\
\hline Temperature HEX2 (K) & 340.6 & 338.7 & 338.7 & 338.7 & 338.7 & 338.7 & 338.7 \\
\hline \multicolumn{8}{|l|}{ Specifications } \\
\hline Distilate rate $(\mathrm{kg} / \mathrm{h})$ & 33 & 35.34 & 39.06 & 34.71 & 37.12 & 37.45 & 37.12 \\
\hline Boilup ratio (kg/kg) & 5 & 4.85 & 4.89 & 4.43 & 3.96 & 3.75 & 3.39 \\
\hline Side draw flowrate $(\mathrm{kg} / \mathrm{h})$ & 107 & 118.23 & 107.63 & 113.49 & 122.74 & 120.15 & 122.04 \\
\hline Liquid flowrate, L1 (kmol/h) & 2.6 & 3.14 & 2.23 & 1.32 & 1.37 & 1.50 & 1.29 \\
\hline Vapor flowrate, V1 (kmol/h) & 2.6 & 3.25 & 3.96 & 1.53 & 1.90 & 1.94 & 2.14 \\
\hline \multicolumn{8}{|l|}{ Product streams } \\
\hline WATER flowrate $(\mathrm{kmol} / \mathrm{h})$ & 5.70 & 5.82 & 5.66 & 5.82 & 5.75 & 5.70 & 5.67 \\
\hline WATER purity (wt\%) & 99.10 & 97.96 & 98.68 & 97.34 & 98.34 & 97.73 & 96.99 \\
\hline FAME flowrate (kmol/h) & 5.83 & 5.83 & 5.83 & 5.83 & 5.83 & 5.83 & 5.83 \\
\hline FAME purity (wt\%) & 100.00 & 100.00 & 100.00 & 99.97 & 99.94 & 99.96 & 99.96 \\
\hline \multicolumn{8}{|l|}{ Recycle stream } \\
\hline TOPALC flowrate $(\mathrm{kmol} / \mathrm{h})$ & 1.10 & 1.10 & 1.12 & 1.08 & 1.12 & 1.10 & 1.07 \\
\hline TOPALC purity (wt\%) & 94.00 & 99.65 & 92.28 & 99.69 & 96.36 & 93.73 & 92.39 \\
\hline \multicolumn{8}{|l|}{ Energy requirements } \\
\hline HEX1 duty (kW) & 95.30 & 68.27 & 58.34 & 88.66 & 103.84 & 99.57 & 95.88 \\
\hline HEX2 duty (kW) & 9.69 & 9.54 & 9.54 & 9.54 & 9.54 & 9.54 & 9.54 \\
\hline Reboiler duty (kW) & 405.59 & 396.48 & 399.20 & 361.64 & 323.39 & 306.23 & 277.20 \\
\hline Condenser duty (kW) & -278.11 & -246.60 & -239.43 & -232.21 & -209.11 & -187.79 & -155.18 \\
\hline Cooler duty (kW) & -205.57 & -200.71 & -200.71 & -200.72 & -200.72 & -200.72 & -200.72 \\
\hline Total heating duty $(\mathrm{kW})$ & 510.58 & 474.29 & 467.08 & 459.84 & 436.77 & 415.34 & 382.62 \\
\hline Total cooling duty (kW) & -483.68 & -447.31 & -440.14 & -432.93 & -409.84 & -388.51 & -355.89 \\
\hline \multicolumn{8}{|l|}{ Key performance indicators } \\
\hline Energy requirements (kwh/ton FAME) & 408.46 & 379.43 & 373.67 & 367.87 & 349.42 & 332.27 & 306.10 \\
\hline Energy savings (\%) & 0.00 & 7.11 & 8.52 & 9.94 & 14.46 & 18.65 & 25.06 \\
\hline Total $\mathrm{CO}_{2}$ emission (ton/year) & 1405 & 1291 & 1277 & 1238 & 1165 & 1105 & 1012 \\
\hline \multicolumn{8}{|l|}{ Economic evaluation } \\
\hline Annual operating cost ( $\mathrm{k} \$ /$ year) & 149.79 & 147.85 & 136.61 & 135.04 & 123.38 & 117.24 & 107.71 \\
\hline Capital cost $(\mathrm{k} \$)$ & 171.60 & 214.17 & 395.36 & 303.21 & 331.79 & 324.52 & 357.06 \\
\hline Total annual cost ( $\mathrm{k} \$ /$ year) & 184.11 & 190.68 & 215.68 & 195.68 & 189.74 & 182.15 & 179.12 \\
\hline
\end{tabular}

Note: S1 - Base case design, S2-S6 - intermediate designs found by SA, S7 - optimal design.

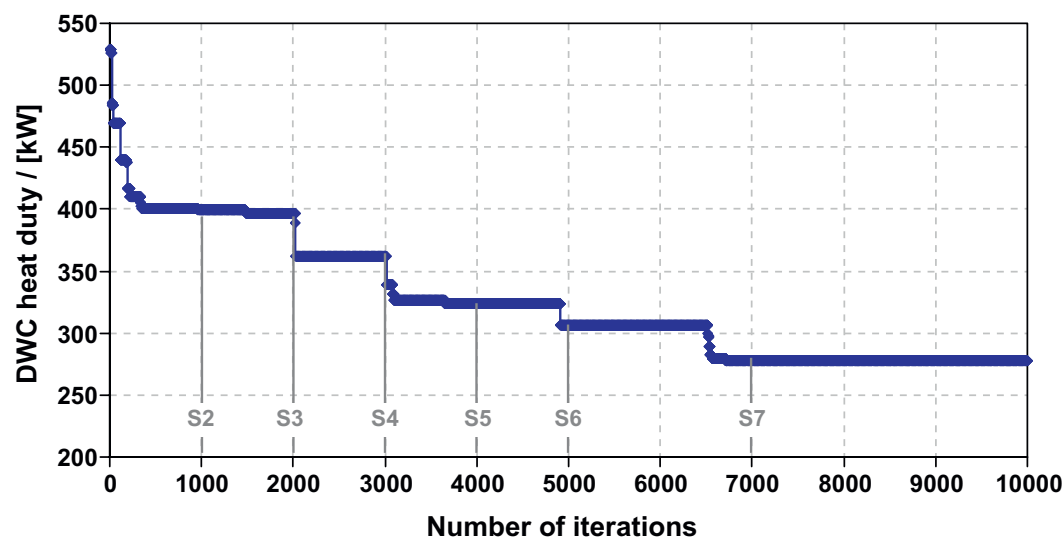

Fig. 7. Evolution of best function value during the course of SA optimization.

optimal ones. This point is important, because in terms of control and operational aspects the control properties of coupled schemes can be improved when the operational conditions fall outside the optimum - designs with minimum energy usage. For this reason, in the selection of operational conditions, a chemical engineer must also take into account the fact that savings in carbon dioxide emissions can be achieved only with additional efforts in the control system. 
According to the results obtained in this study, the best overall design option is the $\mathrm{S7}$ system as it has a low TAC value, the highest energy savings and the lowest $\mathrm{CO}_{2}$ emissions. Although the complex reactive column $\mathrm{S} 7$ has a larger number of stages compared to case $S 1$, the total annual cost is very similar. Thus a full comparative analysis indicates that the best design option is case S7.

\section{Conclusions}

The novel integrated design based on a reactive dividing wall column could be successfully used for the energy efficient production of FAME from waste raw materials reach in FFA. Significant energy savings, of up to $25 \%$ of the base case design, could be achieved by formulating an optimization problem solved by applying the simulated annealing method. Moreover, the integrated reactive DWC alternative proposed in this work allows several important benefits over conventional biodiesel processes:

- Efficient use of the raw materials and equipment: only $15 \%$ excess of methanol, complete conversion of fatty acids, significantly high unit productivity.

- Elimination of all conventional catalyst-related operations such as: catalyst neutralization, separation and disposal of waste salts, as well as waste water treatment.

- Flexible plant that is suitable for a large range of feedstock with very high FFA content, such as palm fatty acid distillate, frying oils, animal tallow and waste vegetable oil.

- Reduced investment costs due to the low number of processing units, and lower energy requirements - up to 25\% energy savings as compared to the R-DWC base case.

\section{Acknowledgment}

The financial support provided by Universidad de Guanajuato and CONACyT (Mexico) is gratefully acknowledged.

\section{References}

[1] Aspen Technology, Aspen Plus: User guide - Volume 1 \& 2, 2009.

[2] Aspen Technology. Aspen physical property system - physical property models; 2009.

[3] Asprion N, Kaibel G. Dividing wall columns: fundamentals and recent advances. Chem Eng Process: Process Intens 2010;49:139-46.

[4] Bildea CS, Kiss AA. Dynamics and control of a biodiesel process by reactive absorption. Chem Eng Res Des 2011;89:187-96.

[5] Bonilla-Petriciolet A, Vazquez-Roman R, Iglesias-Silva G, Hall K. Performance of stochastic optimization methods in the calculation of phase stability analyses for nonreactive and reactive mixtures. Ind Eng Chem Res 2006;45:4764-72.

[6] Bravo-Bravo C, Segovia-Hernández JG, Gutiérrez-Antonio C, Duran AL, BonillaPetriciolet A, Briones-Ramírez A. Extractive dividing wall column: design and optimization. Ind Eng Chem Res 2010;49:3672-88.

[7] Cabrera-Ruiz J, Miranda-Galindo EY, Segovia-Hernández JG, Hernández S, Bonilla-Petriciolet A. Evaluation of stochastic global optimization methods in the design of complex distillation configurations. In: Dritsas I, editor. Stochastic optimization - seeing the optimal for the uncertain, vol. 18. InTech; 2011. p. 441-56.

[8] Dejanović I, Matijašević L, Olujić Ž. Dividing wall column - a breakthrough towards sustainable distilling. Chem Eng Process: Process Intens 2010;49:559-80.

[9] Demirbas AH. Inexpensive oil and fats feedstocks for production of biodiesel. Energy Educ Sci Technol, Part A - Energy Science Res 2009;23:1-13.

[10] Diggelen van RC, Kiss AA, Heemink AW. Comparison of control strategies for dividing - wall columns. Ind Eng Chem Res 2010;49:288-307.

[11] Dimian AC, Bildea CS, Omota F, Kiss AA. Innovative process for fatty acid esters by dual reactive distillation. Comp Chem Eng 2009;33:743-50.

[12] Gadalla MA, Olujic Z, Jansens PJ, Jobson M, Smith R. Reducing $\mathrm{CO}_{2}$ emissions and energy consumption of heat-integrated distillation systems. Environ Sci Technol 2005;39:6860-70.

[13] Gomez-Castro FI, Segovia-Hernandez JG, Hernandez S, Gutierrez-Antonio C, Briones-Ramirez A. Dividing wall distillation columns: optimization and control properties. Chem Eng Technol 2008;31:1246-60.

[14] Hanke M, Li P. Simulated annealing for the optimization of batch distillation processes. Comp Chem Eng 2000;24:1-8.
[15] Hanna MA, Isom L, Campbell J. Biodiesel: current perspectives and future. J Sci Ind Res 2005;64:854-7.

[16] Harmsen J. Process intensification in the petrochemicals industry: drivers and hurdles for commercial implementation. Chem Eng Process 2010;49:70-3.

[17] Hernandez S, Sandoval-Vergara R, Barroso-Munoz FO, Murrieta-Duenasa R, Hernandez-Escoto H, Segovia-Hernandez JG, et al. Reactive dividing wall distillation columns: simulation and implementation in a pilot plant. Chem Eng Process 2009;48:250-8.

[18] Hernandez S, Segovia-Hernandez JG, Juarez-Trujillo L, Estrada-Pacheco JE, Maya-Yescas R. Design study of the control of a reactive thermally coupled distillation sequence for the esterification of fatty organic acids. Chem Eng Commun 2010;198:1-18.

[19] Isopescu R, Woinaroschy A, Draghiciu L. Energy reduction in a divided wall distillation column. Revista de Chimie 2008;59:812-5.

[20] Jena PC, Raheman H, Kumar GVP, Machavaram R. Biodiesel production from mixture of mahua and simarouba oils with high free fatty acids. Biomass Bioenergy 2010;34:1108-16.

[21] Kirkpatrick S, Gelatt Jr CD, Vecchi M. Optimization by simulated annealing. Science 1983;220:671-80.

[22] Kiss AA, Dimian AC, Rothenberg G. Solid acid catalysts for biodiesel production - towards sustainable energy. Adv Synth Catal 2006;348:75-81.

[23] Kiss AA, Rothenberg G, Dimian AC, Omota F. The heterogeneous advantage: biodiesel by catalytic reactive distillation. Topics Catal 2006;40:141-50.

[24] Kiss AA, Dimian AC, Rothenberg G. Biodiesel by reactive distillation powered by metal oxides. Energy Fuels 2008;22:598-604.

[25] Kiss AA. Novel process for biodiesel by reactive absorption. Sep Purif Technol 2009;69:280-7.

[26] Kiss AA, Pragt H, van Strien C. Reactive dividing-wall columns - how to get more with less resources? Chem Eng Comm 2009;196:1366-74.

[27] Kiss AA. Separative reactors for integrated production of bioethanol and biodiesel. Comp Chem Eng 2010;34:812-20.

[28] Kiss AA. Heat-integrated reactive distillation process for synthesis of fatty esters. Fuel Process Technol 2011;92:1288-96.

[29] Kiss AA, Bildea CS. Integrated reactive absorption process for synthesis of fatty esters. Biores Technol 2011;102:490-8.

[30] Kiss AA, Bildea CS. A control perspective on process intensification in dividingwall columns. Chem Eng Process: Process Intens 2011;50:281-92.

[31] Kiss AA, Bildea CS. A review on biodiesel production by integrated reactive separation technologies. J Chem Technol Biot 2012, in press.

[32] Kiss AA, Suszwalak DJ-PC, Enhanced bioethanol dehydration by extractive and azeotropic distillation in dividing-wall columns, Separation \& Purification Technology, 2011, Article in press, DOI: 10.1016/j.seppur.2011. 10.022

[33] Kiss AA, Suszwalak DJ-PC. Innovative dimethyl ether synthesis in a reactive dividing-wall column. Comput Chem Eng 2012, in press. doi:10.1016/ j.compchemeng.2011.11.012

[34] Kulkarni MG, Dalai AK. Waste cooking oil-an economical source for biodiesel: A review. Ind Eng Chem Res 2006;45:2901-13.

[35] Metropolis N, Rosenbluth A, Rosenbluth M, Teller A, Teller E. Equation of state calculations by fast computation machines. J Chem Phys 1953;21:1087-92.

[36] Mueller I, Kenig EY. Reactive distillation in a dividing wall column - rate-based modeling and simulation. Ind Eng Chem Res 2007;46:3709-19.

[37] Narasimharao K, Lee A, Wilson K. Catalysts in production of biodiesel: a review. J Biobased Mater Bioenergy 2007;1:19-30.

[38] Noeres C, Kenig EY, Gorak A. Modelling of reactive separation processes: reactive absorption and reactive distillation. Chem Eng Process 2003;42:157-78.

[39] Phan AN, Phan TM. Biodiesel production from waste cooking oils. Fuel 2008;87:3490-6.

[40] Rangaiah G. Evaluation of genetic algorithms and simulated annealing for phase equilibrium and stability problems. Fluid Phase Equilibria 2001;187188:83-109.

[41] Qiu Z, Zhao L, Weatherley L. Process intensification technologies in continuous biodiesel production. Chem Eng Process: Process Intens 2010;49:323-30.

[42] Rong BG, Turunen I. A new method for synthesis of thermodynamically equivalent structures for Petlyuk arrangements. Chem Eng Res Des 2006;84:1095-116.

[43] Sahoo PK, Das LM. Process optimization for biodiesel production from Jatropha, Karanja and Polanga oils. Fuel 2009;88:1588-94.

[44] Schembecker G, Tlatlik S. Process synthesis for reactive separations. Chem Eng Process 2003;42:179-89.

[45] Sharma YC, Singh B, Korstad J. Latest developments on application of heterogenous basic catalysts for an efficient and eco friendly synthesis of biodiesel: A review. Fuel 2011;90:1309-24.

[46] The Mathworks Inc., Global optimization toolbox user's guide, Natick US, 2011.

[47] R. Turton, R. C. Bailie, W. B. Whiting, J. A. Shaeiwitz, Analysis, synthesis and design of chemical processes, second ed., Prentice Hall, USA, 2004.

[48] Vlad E, Bildea CS, Plesu V, Marton G, Bozga G. Design of biodiesel production process from rapeseed oil. Revista de Chimie 2010;61:595-603.

[49] Vyas AP, Verma JL, Subrahmanyam N. A review on FAME production processes. Fuel 2010;89:1-9.

[50] Wei-Zhong A, Xi-Gang Y. A simulated annealing-based approach to the optimal synthesis of heat-integrated distillation sequences. Comp Chem Eng 2009;33:199-212.

[51] X-S Yang. Nature-inspired metaheuristic algorithms. UK: Luniver Press 2008. 
[52] Yildirim O, Kiss AA, Kenig EY. Dividing wall columns in chemical process industry: a review on current activities. Separation Purification Technol 2011;80:403-17.

[53] Yuan W, Hansen AC, Zhang Q. Vapor pressure and normal boiling point predictions for pure methyl esters and biodiesel fuels. Fuel 2005;84:943-50.
[54] Zabeti M, Daud WMAW, Aroua MK. Activity of solid catalysts for biodiesel production: A review. Fuel Process Technol 2009;90:770-7.

[55] Zhang Y, Dube MA, McLean DD, Kates M. Biodiesel production from waste cooking oil: 2. Economic assessment and sensitivity analysis. Bioresour Technol 2003;90:229-40. 